\title{
3D Thermal Finite Element Analysis of the SLM 316L Parts with Microstructural Correlations
}

\author{
Ketai He $(1 D)$ and Xue Zhao \\ School of Mechanical Engineering, University of Science and Technology Beijing, Beijing, China \\ Correspondence should be addressed to Ketai He; heketai@ustb.edu.cn
}

Received 9 May 2018; Accepted 8 July 2018; Published 3 October 2018

Academic Editor: Yimin Zhou

Copyright ( 2018 Ketai He and Xue Zhao. This is an open access article distributed under the Creative Commons Attribution License, which permits unrestricted use, distribution, and reproduction in any medium, provided the original work is properly cited.

\begin{abstract}
In this study, a multitrack and multilayer finite element model was developed to simulate the temperature field and molten pool contours during selective laser melting (SLM) of 316L stainless steel powder under different scanning strategies. The simulated temperature field and its evolution over time were compared with experimental measurement results. Furthermore, a correlation was established by the presented results between the predicted thermal behavior and the microstructure of SLM specimens. It was found that the maximum temperature of the molten pool rose slightly with the increase of scanning tracks, but when laser scanned multilayer, the maximum temperature rose first and then decreased. There are large columnar crystals in molten pools, growing in the direction of the maximum temperature gradient. The microstructure defects are more likely to occur at the bonding regions between adjacent layers and islands, where the heat and stress are concentrated. Moreover, the results also showed that the scanning strategy affects the microstructure and microhardness. Also, the SLM 316L parts under the S-shaped strategy had finer grains and a higher Vicker hardness than that formed under the island strategy.
\end{abstract}

\section{Introduction}

Selective laser melting (SLM), as an important branch of additive manufacturing technique, is a highly promising technology. It integrates advanced technologies, such as powder metallurgy technology, laser technology, computer-aided design and manufacturing technology, and computer control technology. SLM technique is based on local melting of metal powder bed by a high-energy laser beam, and it is widely used in fields such as automotive, aerospace, defense, and biomedical. The SLM-processed complex parts can be fabricated directly by powder material and put into use without postprocessing treatment [1].

However, in the process of SLM, powder materials experienced fast local melting and solidification, which results in severe temperature gradients. As a result, the stress of parts is increased, and defects such as pores and cracks are likely to occur, which seriously affects the manufacturing quality of parts. The problems above become one of the important factors restricting the development of SLM [2]. Besides, the processing parameters such as laser power, scanning speed, scanning strategy, and preheat temperature all affect the distribution of the temperature field to a great extent, thereby affecting the quality of manufacturing, too. These parameters are usually optimized by experimental means, but the process is obviously time-consuming and costly. Using experimental methods, it is still hard to obtain the dynamic temperature change process of the SLM material inside the powder bed [3-5]. Meanwhile, up to now, some researchers mainly focus on the effect of processing parameters on the microstructures and the mechanical properties of the SLM parts, but the formation mechanism of defects formed during the SLM process was not clarified systematically. The Lawrence Livermore Laboratory in the United States used physical models and simulation experiments to study how the melt flow in the molten pool causes defects, such as voids, material splashes, and cracks $[6,7]$. It was demonstrated that the effect of recoil pressure and the Marangoni flow on the molten pool contours. When the direction of the scanning track was changed, the laser intensity should be reduced, otherwise additional thermal deposition may result in a deep and narrow depression. Therefore, in recent years, several finite 
TABLE 1: Chemical composition of the traditional wrought 316L and the powder used for SLM-produced 316L (WT. \%).

\begin{tabular}{lcccccccrrrr}
\hline Material & $\mathrm{Ni}$ & $\mathrm{Cr}$ & $\mathrm{Mo}$ & $\mathrm{C}$ & $\mathrm{Mn}$ & $\mathrm{Si}$ & $\mathrm{P}$ & $\mathrm{S}$ & $\mathrm{N}$ & $\mathrm{Fe}$ \\
\hline Powder & 11.08 & 17.36 & 2.02 & 0.013 & 1.19 & 0.36 & 0.032 & 0.002 & 0.052 & $\mathrm{Bal}$ \\
Wrought & 11.14 & 17.25 & 2.08 & 0.016 & 1.23 & 0.38 & 0.035 & 0.003 & 0.054 & $\mathrm{Bal}$. \\
\hline
\end{tabular}

TAble 2: Processing parameters during SLM.

\begin{tabular}{lc}
\hline Parameter & Value \\
\hline Laser spot size $D$ & $200 \mu \mathrm{m}$ \\
Laser power $P$ & $300 \mathrm{~W}$ \\
Scanning speed $V$ & $2000 \mathrm{~mm} / \mathrm{s}$ \\
Hatch spacing $H$ & $0.12 \mathrm{~mm}$ \\
Powder layer thickness $T$ & $0.02 \mathrm{~mm}$ \\
Melting point Tm & $1653 \mathrm{~K}$ \\
\hline
\end{tabular}

element models (FEMs) of the SLM process have been developed, focusing on specific topics (molten pool, heat affected zone, grain morphology, residual stresses, etc.), which are the most commonly used methods for predicting the temperature field and improving the quality of parts.

Shi et al. developed a three-dimensional transient FEM to simulate temperature field and molten pool size in the process of SLM. The simulation results are consistent with the experimental results, which highlight the validity of this simulation [8]. However, the temperature field of multilayer during SLM has not yet been studied by using this model. Meanwhile, Liu et al. and $\mathrm{Hu}$ et al. proposed a single-track and multilayer FEM for SLM. They found that subsequent laser scanning of a new layer alters the temperature field in the previous layers $[9,10]$. But the integral multitrack and multilayer temperature distribution has not been further studied. Foroozmehr et al. simulated the effect of the process parameters on the size of molten pool in SLM, and the heat transfer and material morphology inside the molten pool were comprehensively considered [11]. It was found that as the laser power increases or the scanning speed decreases, the speed of melt zone increasing in length is faster than that in width. Thus, the different parameters can result in different microstructures and further lead to different mechanical properties. A thermomechanical simulation model was established to predict the temperature distribution and stress fields in SLM by Hussein et al. [12]. The cyclic melting and cooling rates result in high von Mises stress. Parry et al. used the thermomechanical simulation model to investigate the influence of the scanning strategy on the residual stress of SLM parts. The results showed that a shorter path can be taken to reduce the residual stress [13].

Currently, most of the reported simulated works were conducted in a single-layer or single-track and multilayer conditions. However, limited reports focused on the integrated temperature field distribution of multitrack and multilayer in the SLM process, which is more consistent with the actual layer-by-layer printing conditions. Some scholars investigated the mechanism of grain growth, the molten pool contours, and the effect of microstructure on the mechanical behavior through experimental means $[5,14,15]$. However, the internal connection between the thermal behavior and microstructure characteristic of SLM parts has not been studied enough. Besides, there are few studies on the influence of different scanning strategies on the temperature distribution, and there is no more effective method to verify the validity of the simulation results by combining the experimental method.

This paper is aimed at associating the thermal behavior with microstructure characteristic of the SLM parts. Thus, a 3D transient FEM was developed in the COMSOL Multiphysics simulation software to predict the temperature field distribution and analyze molten pool contours. In order to explore the impact of different scanning strategies on the temperature distribution, two groups of samples with 316L SS were manufactured by SLM, respectively: one group was under S-shaped path, and the other was under island path. The FEM was designed as multitrack and single-layer style and multitrack and multilayer style. Temperaturedependent physical properties (specific heat capacity, thermal conductivity) of material and latent heat of fusion are taken into account. Moreover, the microstructure was observed, the microhardness was measured, and the relationship between grain growth mechanism and temperature field distribution was analyzed.

The second part introduces the experimental procedure and experimental results. The third part is FEM analysis. The fourth part is to simulate the correlation between thermal behavior and microstructure of parts.

\section{Experimental Procedure}

2.1. Materials. Multitrack samples were manufactured on a SLM machine (EP-M100, e-Plus 3D). The machine is equipped with a laser power of $300 \mathrm{~W}$ continuous wavelength of $1064 \mathrm{~nm}$ ytterbium fiber laser. Focusing optics produces a focused beam spot size of $70 \mu \mathrm{m}$ in diameter. The region which is irradiated by laser beam is melted and solidified, forming melting tracks, while the other regions remain powder state.

In this work, the material in use was gas-atomized 316L stainless steel powder. The diameter of particles is between $15 \mu \mathrm{m}$ and $53 \mu \mathrm{m}$, and the chemical compositions are presented in Table 1 . It is convenient to identify the microstructure within the samples owing to the $316 \mathrm{~L}$ powder's single-phase austenite.

2.2. Experimental Methods. Based on a series of preliminary experiments, the processing parameters used to prepare samples are seen in Table 2. Two different scanning strategies were applied: S-shaped and island, which are illustrated 


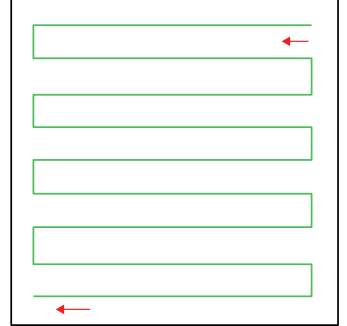

(a) S-shaped scanning strategy

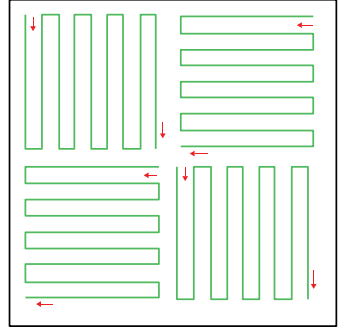

(b) Island scanning strategy
FIgURE 1: Scanning strategies during the SLM process.

schematically in Figures 1(a) and 1(b), respectively. The scanning, vertical, and building directions are referred hereafter as $\mathrm{X}, \mathrm{Y}$, and $\mathrm{Z}$, respectively.

The specimens were cut through the inner, and then the cross sections were polished on the sandpaper and etched (using ferric chloride etchant, i.e., $50 \mathrm{ml}$ distilled water, $50 \mathrm{~g}$ $\mathrm{FeCl}_{3}$, and $50 \mathrm{ml} \mathrm{HCl}$ ). Microstructure of the cross section was observed on an optical microscope (OM) and a scanning electron microscope (SEM) [14].

The electron back-scattered diffraction (EBSD) measurements were carried out at $20 \mathrm{kV}$ with a scanning step of $2 \mu \mathrm{m}$. The samples were electropolished using 20\% perchloric acid in liquid nitrogen for about 30 seconds prior to the measurements. In order to obtain the grain orientations and the grain-boundary densities, the EBSD data were analyzed by TSL OIM Analysis 7.

\section{Description of 3D Thermal Finite Element Model}

The numerical solution was carried out using the COMSOL Multiphysics heat transfer module to obtain a thorough understanding of thermal behaviors. The 3D FEM was meshed and swept by a free quadrilateral mesh as shown in Figure 2. The thickness of a layer can be expressed by only one thin element, and an appropriate simplified model can obtain the dynamic temperature field of the SLM manufacturing process quickly. The mesh of the laser scanning area is refined locally, and coarser mesh is used for the surrounding loose powder, reducing the degree of freedom of the solution, which ensures the mesh a sufficient density to obtain sufficient calculation accuracy and reduce computational time.

In this study, the temperature fields and molten pool morphology under two kinds of scanning strategies in the process of SLM were simulated. Figure 3 shows the schematic diagram of multitrack and multilayer manufacturing process. In addition, due to the complexity of some modeling parameters in the process of actual processing, it is impossible to make reasonable settings. The simulating results need to be constantly revised and improved in the experiment and application.

3.1. Thermal Modeling. The 316L stainless steel powder absorbs abundant energy of the laser beam and forms a molten pool that joins adjacent scanning tracks, and the heat dissipates during this process mainly through conduction, convection, and radiation. The temporal and spatial distribution of the temperature field satisfies the classical Fourier heat conduction equation [16]:

$$
\rho c \frac{\partial T}{\partial t}=\frac{\partial}{\partial x}\left(k \frac{\partial T}{\partial x}\right)+\frac{\partial}{\partial y}\left(k \frac{\partial T}{\partial y}\right)+\frac{\partial}{\partial z}\left(k \frac{\partial T}{\partial z}\right)+Q,
$$

where $\rho$ is the material density $\left(\mathrm{kg} / \mathrm{m}^{3}\right) ; c$ is the heat capacity coefficient $(\mathrm{J} / \mathrm{kgK}) ; T$ is temperature; $t$ is the interaction time; $k$ is the heat conductivity coefficient $(\mathrm{W} / \mathrm{mK})$; and $Q$ is the volumetric heat generation $\left(\mathrm{W} / \mathrm{m}^{3}\right)$.

The initial condition of uniform temperature distribution at time $t=0$ can be set as

$$
\left.T(x, y, z, t)\right|_{t=0}=T_{0},
$$

where $T_{0}$ is the ambient temperature taken as $323 \mathrm{~K}\left(50^{\circ} \mathrm{C}\right)$.

The heat loses in powder bed mainly through thermal conduction, thermal convection, and thermal radiation, belonging to the third type of boundary conditions.

$$
-k \frac{\partial T}{\partial z}+h\left(T-T_{0}\right)+\sigma \varepsilon\left(T^{4}-T_{0}^{4}\right)=Q
$$

where $\varepsilon$ is the thermal radiation coefficient of 316L stainless steel powder which is taken as 0.25 ; $h$ is the convection heat transfer coefficient; $\sigma$ is the Stefan-Boltzmann constant $\left(5.67 \times 10^{-8} \mathrm{~W} /\left(\mathrm{m}^{2} * \mathrm{~K}^{4}\right)\right)$.

Because the layers are built on a large powder bed which was assumed as a continuous and homogeneous media, the heat transfer at the bottom of loose powder can be negligible.

$$
-\left.k \frac{\partial T}{\partial z}\right|_{z=\propto}=0
$$

3.2. Heat Source Modeling. The moving laser beam was considered as the Gaussian distribution of energy which is the most common beam profile, as shown in Figure 4.

$$
q=\frac{2 A P}{\pi R^{2}} \exp \left(-\frac{2 r^{2}}{R^{2}}\right)
$$

where $q$ is the input heat flux; $R$ is the laser beam radius; $A$ is the absorptivity of the $316 \mathrm{~L}$ stainless steel which is taken as 0.2 ; and $r$ is the radial distance from the beam center which can be applied as

$$
r=\left(x-x_{0}\right)^{2}+\left(y-y_{0}\right)^{2} .
$$

3.3. Material Properties. In the process of SLM, the temperature-dependent thermal conductivity and specific heat capacity of the material were defined. The phase transformation occurs when the material is completely melted, and the latent heat is released and absorbed during the phase transformation process, affecting the temperature distribution. Therefore, it is necessary to take the latent heat of fusion into account. 


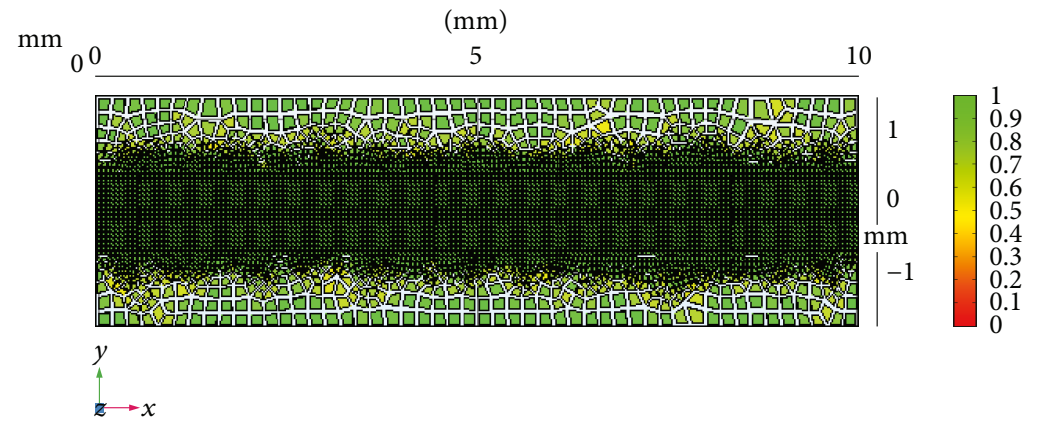

Figure 2: 3D FE mesh used for the numerical simulation of the SLM process.

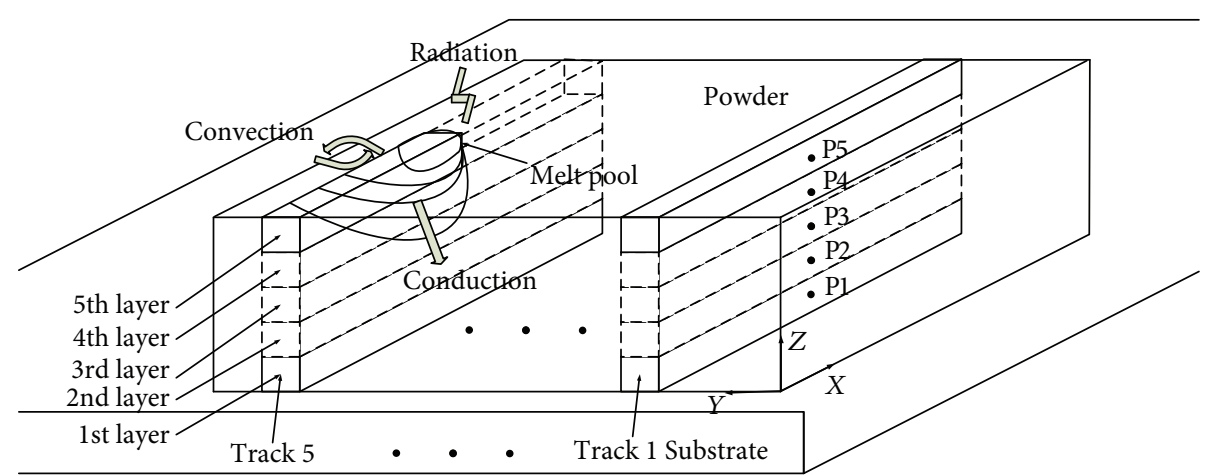

FIGURE 3: Schematic of multitrack and multilayer manufacturing during the SLM process.

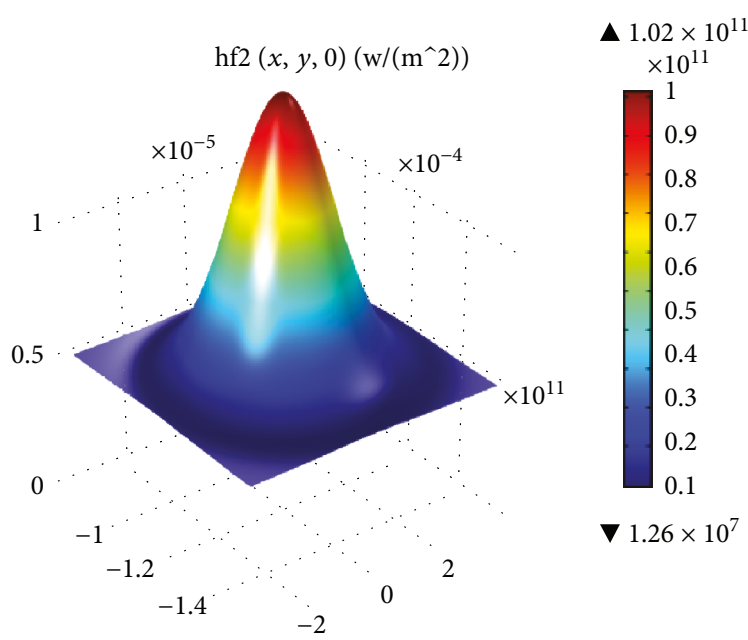

Figure 4: Gaussian laser energy density.

In this article, the method of equivalent specific heat capacity is applied. The specific heat capacity $C_{e}$ at this stage includes two parts: the specific heat capacity of the object $C_{s}$ and the specific heat capacity $L_{0}$ caused by latent heat.

$$
\begin{gathered}
C_{e}=C_{s}+C_{0}, \\
L_{0}=\frac{L}{\left(T_{\mathrm{L}}-T_{\mathrm{s}}\right)},
\end{gathered}
$$

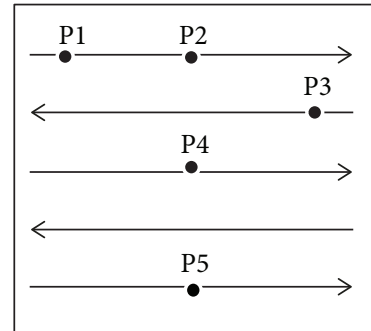

(a) S-shaped strategy

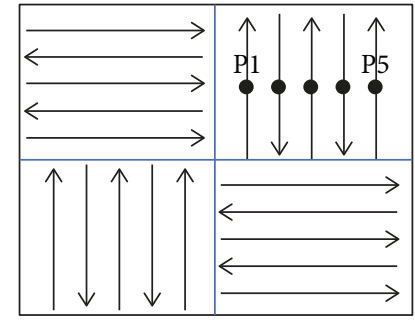

(b) Island strategy
FIGURE 5: Laser scanning strategies.

where $T_{\mathrm{L}}$ and $T$ s are the temperature of liquidus and solidus, which are taken as $1723 \mathrm{~K}$ and $1650 \mathrm{~K}$, respectively; $L$ is the latent heat and is taken as $273,000 \mathrm{~J} / \mathrm{mm}^{3}$.

\section{Results and Discussion}

\subsection{Analysis of the FE Simulation Results in Single Layer}

4.1.1. Effect of Scanning Strategy on the Temperature Distribution. In this work, the S-shaped and island scanning strategies are selected. The S-shaped scanning strategy is commonly used in the SLM process, with the scanning lines starting from the opposite side, and all the scanning lines are parallel to each other, as shown in Figure 5(a). In addition, the powder bed is divided into four square areas in the island scanning strategy, and each square area is under S-shaped path [3]. The five points marked in 


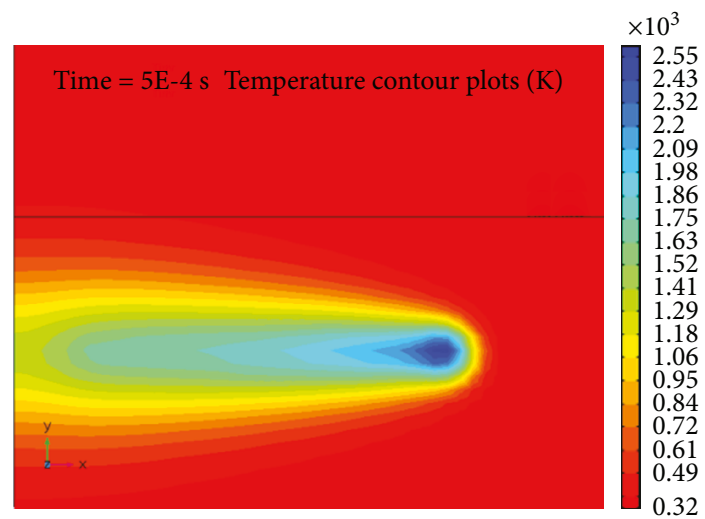

(a)

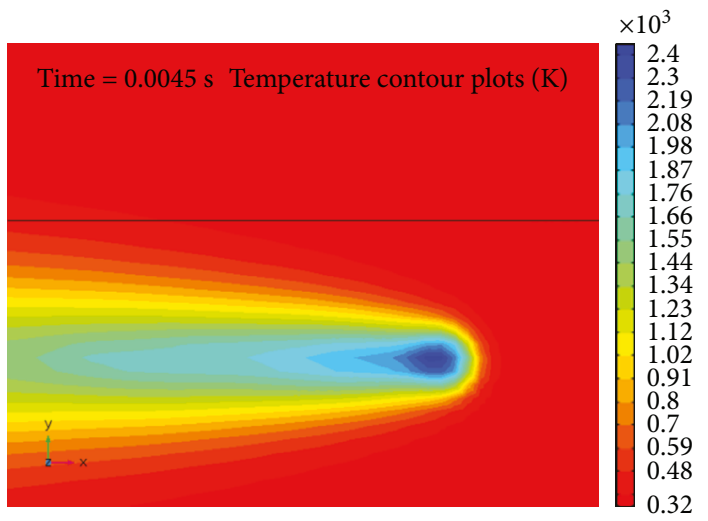

(b)

Figure 6: Temperature contour plots during the multitrack depositing process when laser irradiates the points P1 and P2.

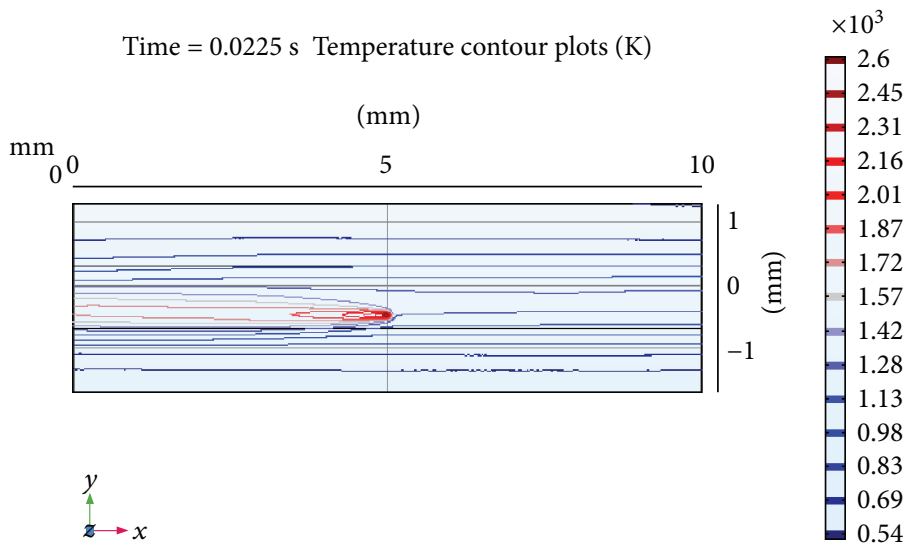

(a)

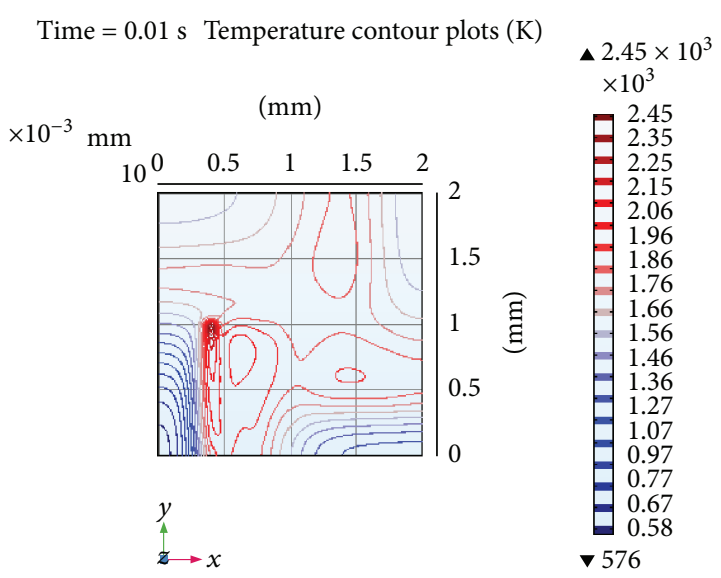

(b)

FIgURE 7: Temperature contour plots: (a) S-shaped scanning strategy and (b) island scanning strategy.

Figure 5(b) are points P1, P2, P3, P4, and P5 from left to right.

In the SLM process, the temperature distribution in the powder bed changes rapidly with time and space. The molten pool moves along with the laser beam, and its shape is similar to comet tail profile (see Figure 6). The forepart temperature contours of the molten pool are more intense than the rear side, indicating that the temperature gradient in forepart of the moving laser beam is much larger. This phenomenon can be owed to the fact that the thermal conductivity of the untreated powder in front of the laser is much lower than the molten material [17].

Figures 6(a) and 6(b) further show that the transient temperature distribution on the top view of the molten pool as laser beam reaches point $\mathrm{P} 1$ and $\mathrm{P} 2(\mathrm{X}=1 \mathrm{~mm}, 5 \mathrm{~mm}$; $\mathrm{Y}=0 \mathrm{~mm} ; \mathrm{Z}=0 \mathrm{~mm})$, respectively. The width of the molten pool is measured from molten region along $y$-axis [18], and the average is about $104 \mu \mathrm{m}$.

Figure 7 (a) depicts the temperature contour plots with time at point P5. With the increasing of the number of scanning tracks, the temperature distribution becomes more and more asymmetric. Besides, the temperature contour plots of the previously laser-scanned tracks are sparse, and the temperature gradient is also smaller. Figure 7(b) shows the temperature contour plots at the time when laser beam reaches the last island. Due to thermal conduction between the islands, the temperature in the scanned area decreases with time, and the heat spreads to the unscanned areas. Meanwhile, there is heat transfer between the scanned and cooled area and neighboring scanning islands. Thus, the temperature distribution of island strategy is wider than that of the S-shaped strategy.

\subsubsection{Effect of Scanning Strategy on the Temperature History.} In the process of S-shaped scanning strategy, it can be seen from Figure 8 that the maximum temperature increases with the increasing of laser scanning tracks, but the range of growth is getting smaller. The maximum temperature is rising rapidly at the start of the next track, owing to that the heat is concentrated when the laser beam changes direction at the scanning corner. The global maximum temperature curve is shown in Figure 8. 


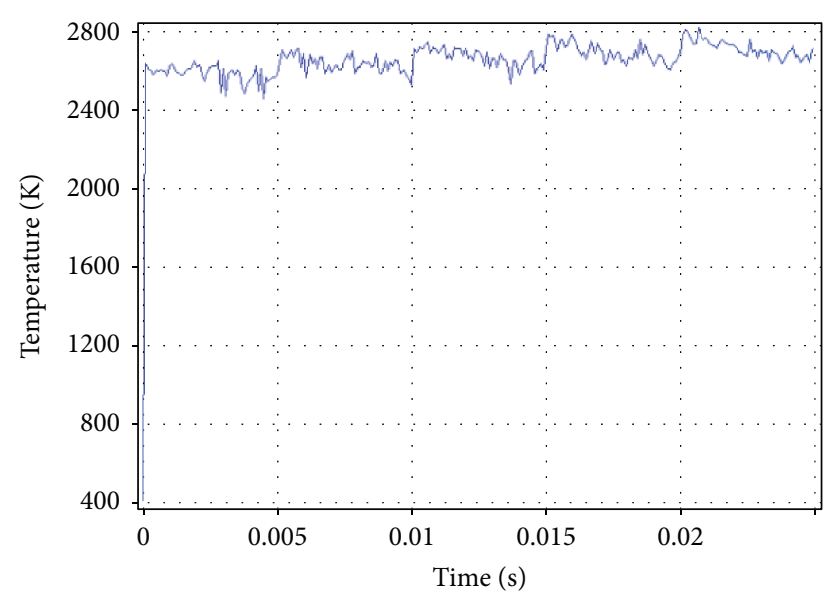

— Maximum

Figure 8: Global highest temperature variation curve.

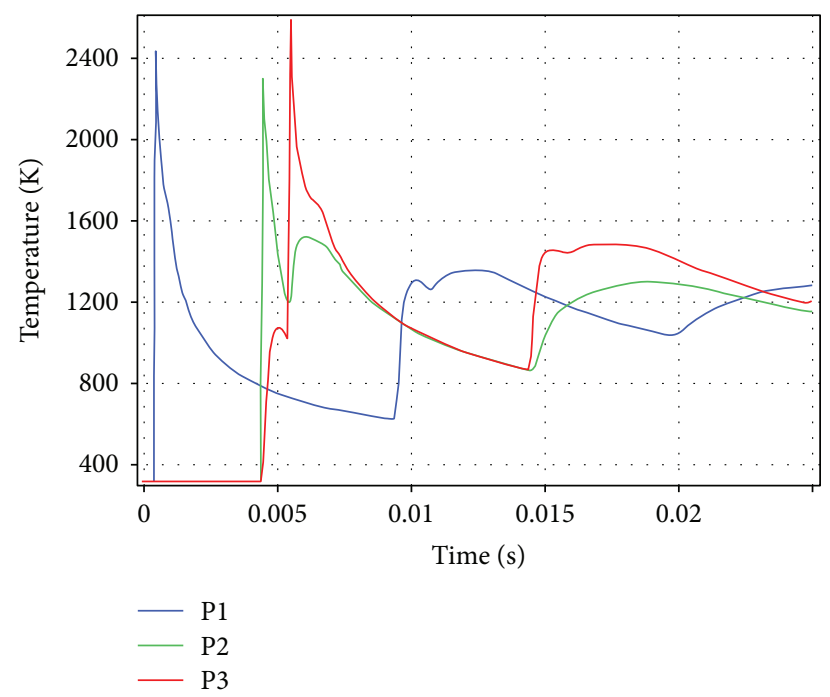

FIgURE 9: Temperature variation curves of P1, P2, and P3.

Figure 9 shows the temperature variation with time at points P1, P2, and P3 during multitrack manufacturing process along the vertical direction. The peak temperatures are at the start of each track. The highest temperature of the molten pool is $2442 \mathrm{~K}$ at point $\mathrm{P} 1$ and exceeds the melting temperature of $316 \mathrm{~L}$ stainless steel $(1653 \mathrm{~K})$. Hereafter, the temperature of point P1 falls below the melting temperature of the material and then cools to the ambient temperature, so do the other four points. However, the maximum temperature of the first track is reduced to $2303 \mathrm{~K}$ at the end. The heat is concentrated when the laser beam changes direction at point $\mathrm{P} 3$. Thus, the maximum temperature of P3 is rising rapidly to $2591 \mathrm{~K}$.

Figure 10 predicts the temperature variation with time at points P2, P4, and P5 under the S-shaped scanning strategy along the longitudinal direction. When the laser beam irradiates point $\mathrm{P} 2$, the maximum temperature is $2439 \mathrm{~K}$, and it drops rapidly to a lower position after the laser beam moves

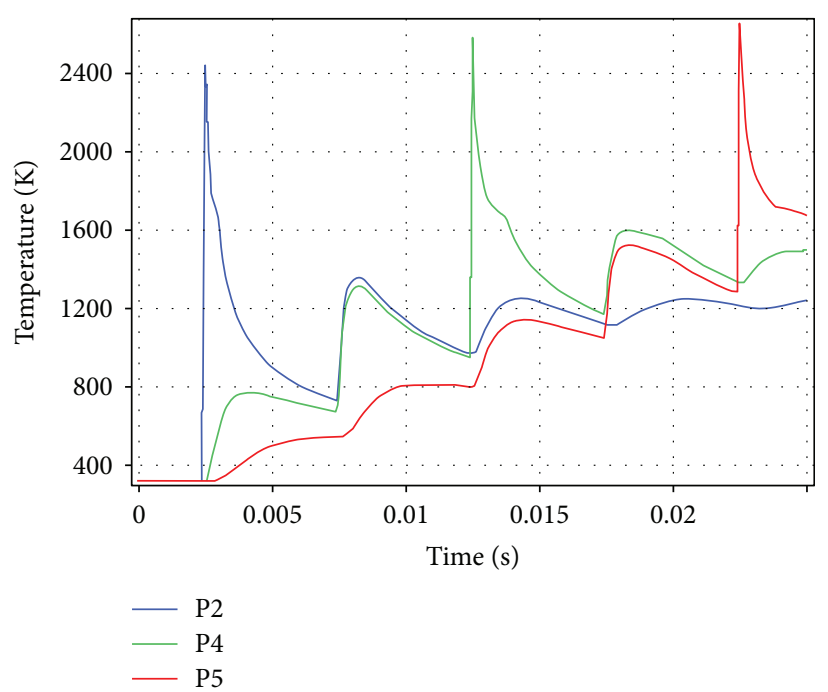

Figure 10: Temperature variation curves of P2, P4, and P5.

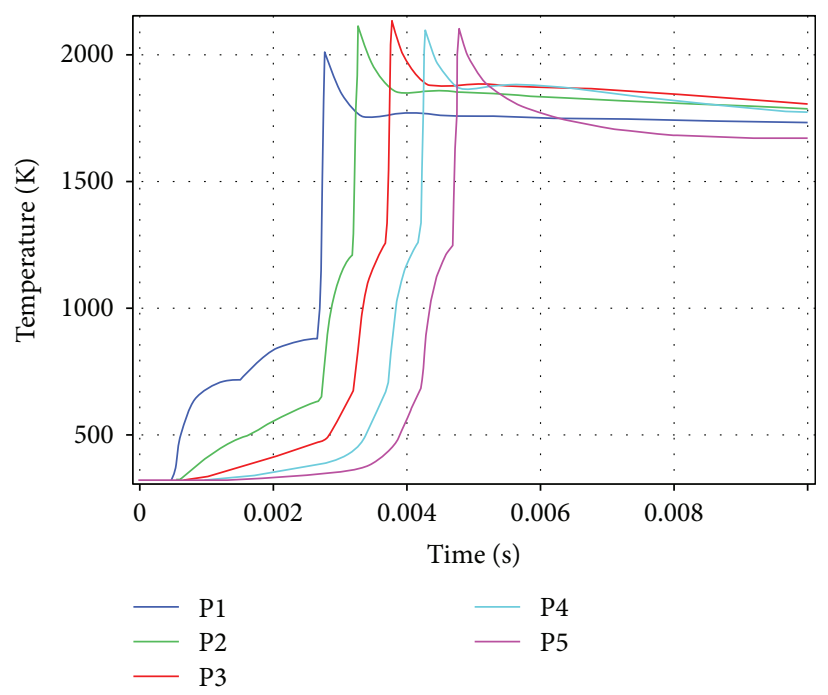

Figure 11: Temperature variations with time at points P1 to P5 under the island scanning strategy.

away. The maximum temperature of points P4 and P5 are $2585 \mathrm{~K}$ and $2656 \mathrm{~K}$, respectively. The highest temperature of $\mathrm{P} 4$ is $146 \mathrm{~K}$ higher than that of point P2, and the highest temperature of point P5 is $71 \mathrm{~K}$ higher than that of point $\mathrm{P} 4$. The figures above indicate that with the increasing of the number of scanning tracks, the increase of the maximum temperature of the molten pool is smaller and smaller and finally tends to be stable.

In the process of island scanning strategy, the highest temperatures of points P1 to P5 are $2013 \mathrm{~K}, 2117 \mathrm{~K}, 2134 \mathrm{~K}$, $2097 \mathrm{~K}$, and $2100 \mathrm{~K}$, respectively, as shown in Figure 11. When the first island is scanned, the energy is transmitted to the unscanned island, resulting in energy diffusion, which reduces the temperature in the region. Especially, the energy is not accumulating on the edge of the island, and the temperature inside the island is higher than the temperature at the island boundaries. 


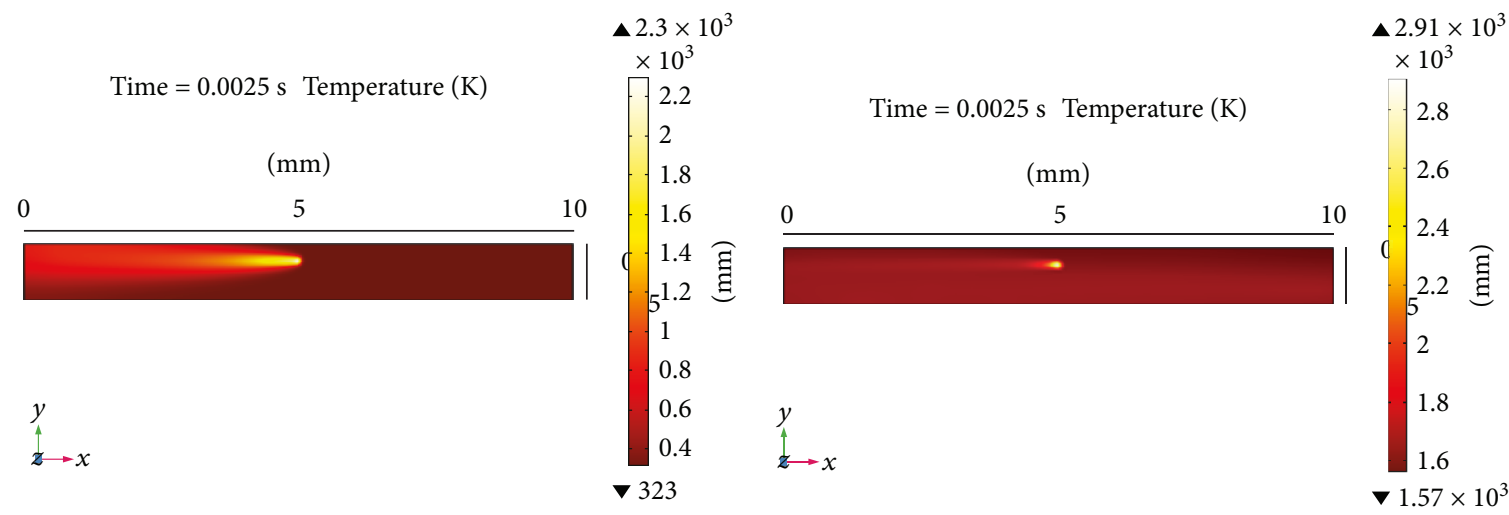

(a)

(b)

FIGURE 12: The distribution of the temperature field corresponding to the midpoint position of the first scanning track in each layer: (a) first layer and (b) fifth layer.

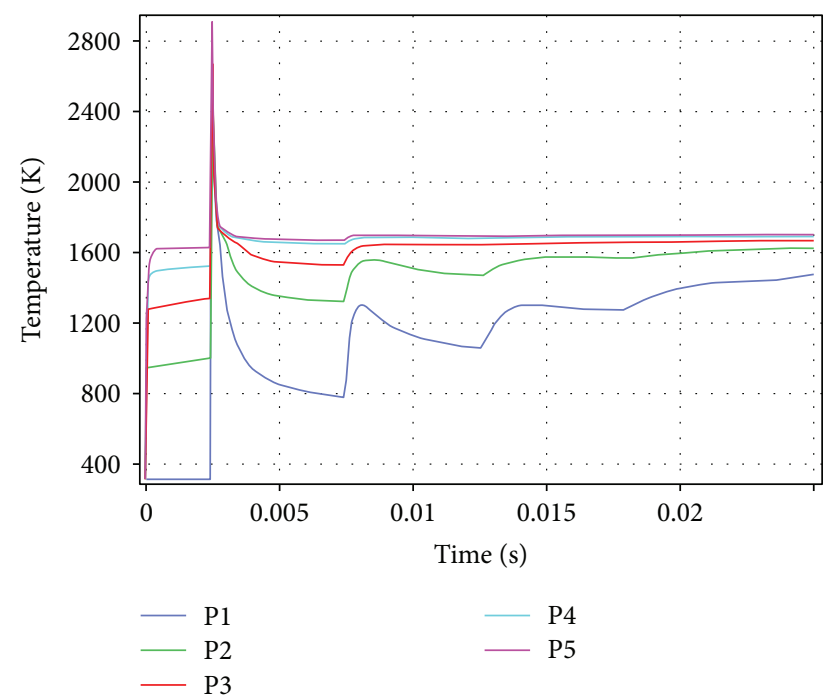

FIGURE 13: Temperature variation curves of the center points of first scanning track in each layer.

\subsection{Analysis of the FE Simulation Results in Multilayer}

4.2.1. Temperature Distribution. In order to study the transfer form of temperature in SLM multilayer processing, this paper uses the COMSOL Multiphysics software to establish a multitrack and multilayer temperature field model, which can reveal the energy transfer process of multilayer processing.

The numerical solution is carried out to obtain a thorough understanding of thermal behaviors. The dimensions of the FEM are $10 \mathrm{~mm} * 3 \mathrm{~mm} * 0.1 \mathrm{~mm}$ with five layers and five tracks in each layer. Figure 12 shows the distribution of the temperature field corresponding to the midpoint position of the first scanning track in the first and fifth layer. It can be seen from Figure 12 that heat is concentrated in the area where it is sintered into a solid. As the number of layers increases, heat spreads to the surrounding powder regions gradually, and the heat-affected regions also become larger and larger.

4.2.2. Temperature History. The highest temperatures at the midpoint of the first scanning track in each of the first to fifth floors are $2275 \mathrm{~K}, 2516 \mathrm{~K}, 2698 \mathrm{~K}, 2863 \mathrm{~K}$, and $2907 \mathrm{~K}$, respectively (see Figure 13). At the beginning of the process, the material is in a powder state, which requires a large amount of laser energy to melt the material, so the maximum temperature of the first layer is lower. But when the laser scans the second layer, the heat of the first layer is transmitted upwards to the new powder after powder coating, which plays the role of preheating. Therefore, the temperature of the second layer is slightly higher than that of the first layer. So does the third, the fourth, and the fifth layer. It is worth noting that solid regions are increasing at the bottom layers, so part of the heat is transferred downwards through the solid regions. Due to the reasons above, the increase in the maximum temperature of the third, the fourth, and the fifth floor reduced gradually.

As laser beam scanning at $0.024 \mathrm{~s}$, the highest temperatures of the same position on each of the first to fifth floors are $2551 \mathrm{~K}, 2722 \mathrm{~K}, 2701 \mathrm{~K}, 2640 \mathrm{~K}$, and $2607 \mathrm{~K}$ in turn. The temperature variation curves of the five layers are shown in Figure 14.

Figure 15 shows the temperature curves at the midpoint of the first scanning track of the first layer, when laser beam scans the same position of the second, third, and fourth layer. This indicates that point P2 is melted twice to bond adjacent tracks.

4.3. Experimental Investigation. The current temperature field simulation technology is still far from the actual processing. The fundamental reason is that the simulation conditions are not considered comprehensively, such as the settings of material properties. Some parameters, such as the absorptivity and emissivity of the material, need to be set based on empirical values, and no specific parameter values can be obtained during the actual processing. Therefore, there are many uncertain factors in the simulation 


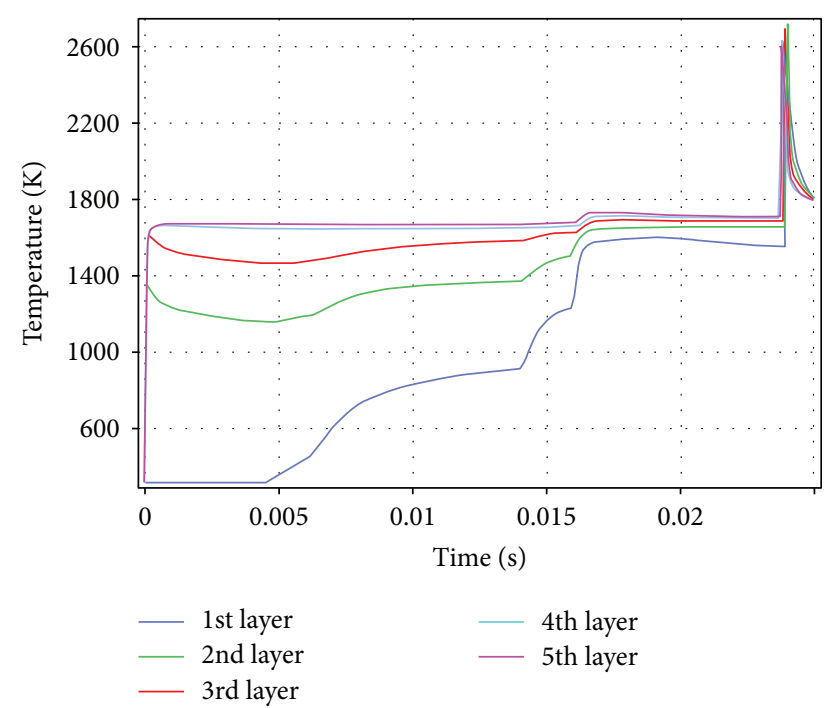

FIgURE 14: The highest temperature variation curves of five layers.

process that affect the accuracy and effectiveness of the simulation model.

In order to ensure that the simulation model is accurate and effective, it is necessary to combine experimental methods to set the same processing parameters with the simulation model for experimentation. To achieve the purpose of verifying the validity of the simulation model, we need to prepare metallographic specimens, observe the microstructure of the specimens, and compare them with simulation results. This process can be combined with the experimental results to modify the model parameters continuously so that the simulation model is in good agreement with the actual machining process.

4.3.1. Optical Micrographs. In this experiment, two different scanning strategies were used to fabricate two kinds of specimens. Sample 1 was under the S-shaped strategy, and sample 2 was under the island strategy. 3D optical micrographs showing the three orthogonal sections (X-Y plane, X-Z plane, and Y-Z plane) are displayed in Figures 16(a) and 16(b).

Figure 17(a) shows the microscopic structure of the Y-Z plane of sample 1, and half cylindrical contours are formed because of the hatch overlapped regions [19]. In the SLM process, molten pools are generated by the radiation of laser beam, which are connected to each other. Samples are composed of many molten pools, and each pool contains several grains, as indicated in Figure 17(a). The molten pool boundaries are noticeable after etching. Molten pools' width is similar to each other (about $100 \mu \mathrm{m}$ ), depending on printing parameters, such as the input power, the laser beam size, and the exposure time $[20,21]$. Almost all of the powder is melt by the laser beam, whereas some pores and cracks still existed at the bottom of the molten pool.

According to Figure 17(b), melted tracks are stacked layer by layer along the manufacturing direction. In the SLM process, the depth of molten pools (about $80 \mu \mathrm{m}$ ) are deeper than the layer thickness, so the layers can be well connected together. Due to the cumulative effect of heat, holes,

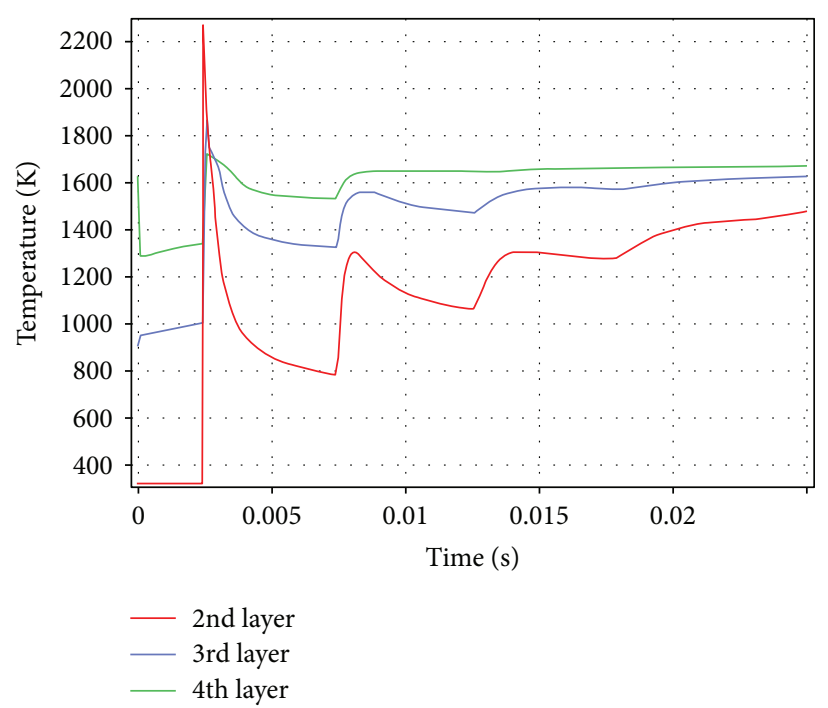

FiguRE 15: The highest temperature variation curves of the 2nd, 3rd, and 4th layer.

cracks, and other defects are easily formed at the metallurgical joint between layers, as marked in Figure 17(b) [22]. The growth direction of grains is substantially perpendicular to the molten pool boundaries, along the maximum temperature gradients. Grains are stretched along adjacent layers in the manufacturing direction, and a large number of grains existing at the molten pool boundaries indicated an epitaxial growth of new grains from adjacent top layers. The epitaxial growth is strongly influenced by the temperature gradient and the curvature of the molten pool. The new zone prevents the continuation of the epitaxial growth, and the new zone has a higher temperature gradient and a lower solidification rate at the bottom of the molten pool. Meanwhile, the different curvature between the bottom and upper of the molten pool may prevent the epitaxial growth of grains.

Optical micrograph of top of the sample 2 shows clear solidification tracks of S-shaped. The melted tracks are parallel and overlapping with each other in the horizontal X-Y plane, as shown in Figure 18(a). The molten pool presents an arc-shaped configuration, which can be attributed to the Gaussian energy distribution of the laser beam [23]. In order to get a further understanding of the solidification behavior of the molten pool, optical images show that there are large columnar crystals in molten pools, indicating an epitaxial growth of new grains from remelted areas, growing in the direction of the maximum temperature gradient through the boundaries of molten pools. In addition, the heat is concentrated at the bottom of the molten pool, resulting into cracks, pores, and other defects at the bottoms and boundaries of molten pools $[6,24]$. The defects are indicated by black arrows in Figure 18(b).

At higher magnifications, two types of molten pool boundaries can be identified in Figure 19 typical for the SLM process. The molten pool boundaries of sample 2 were generated from layer-by-layer overlapping along the $z$-axis which are called as "layer-layer" molten pool boundaries. Correspondingly, those generated through track-by-track overlapping in the X-Y plane are referred to as "track-track" 


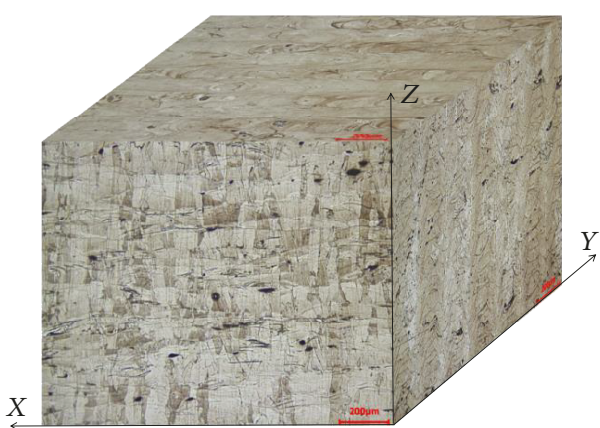

(a)

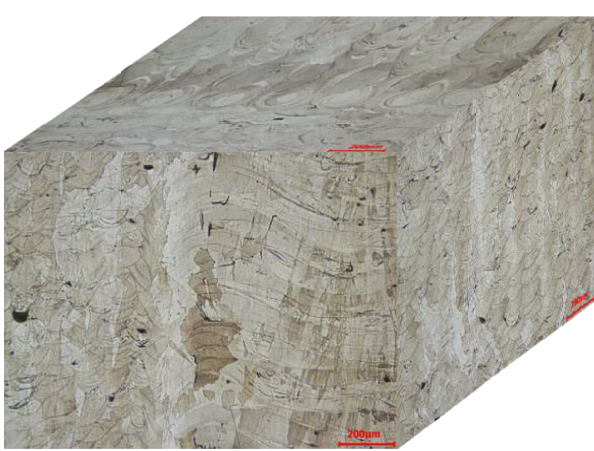

(b)

FIGURE 16: Representative optical micrographs of the SLM 316L SS on the three orthogonal planes showing the X-Y, Y-Z, and X-Z views of (a) sample 1 and (b) sample 2.

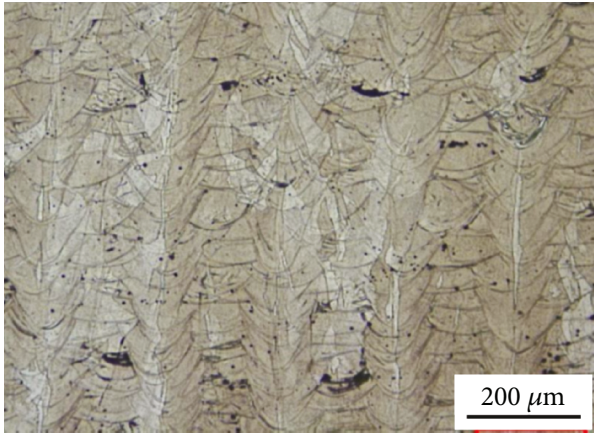

(a)

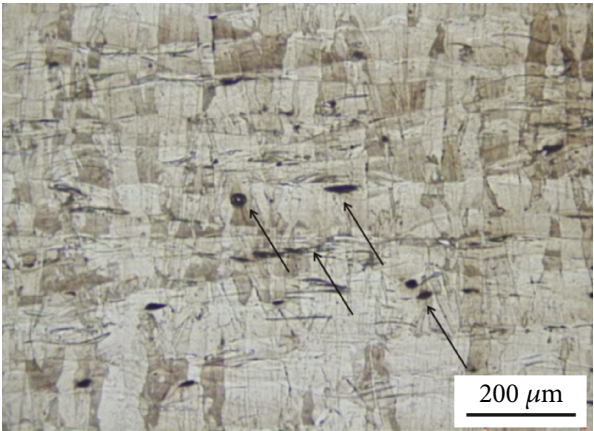

(b)

Figure 17: (a) Optical micrographs of the Y-Z plane and (b) of the X-Z plane of sample 1.

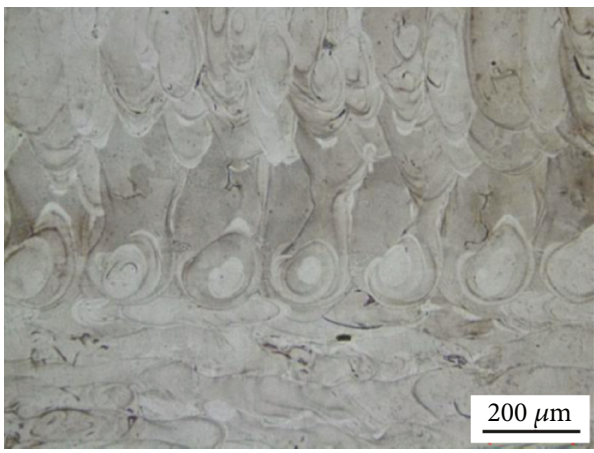

(a)

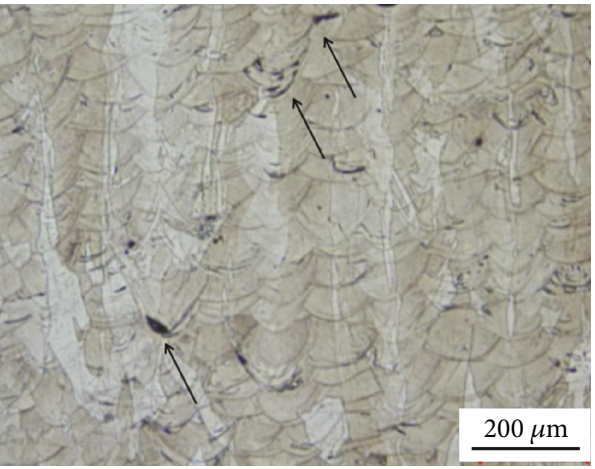

(b)

Figure 18: (a) Characteristic optical micrographs of the X-Y plane and (b) of the Y-Z plane of the pool boundaries in sample 2.

molten pool boundaries [25]. Melt tracks were partially remelted, resulting in an increase in density of SLM parts. As shown in Figure 19, the zone " 1 " is part of the molten pool "B," which was remelted by the adjacent molten pool "A." Similarly, the zone " 3 " is part of the molten pool "B," which was remelted by the adjacent molten pool "C." The zone " 2 " is part of the molten pool " $\mathrm{B}$," which was remelted by following laser scans of the adjacent top layer [26].
It is easy to observe that different regions of the molten pool are characterized by different crystallization types; a typical cellular structure was found in zone A, and cellular dendrites was in zone B marked in Figure 20. Such structures, widely existed in laser processed parts, are mainly due to the elevated cooling speed $(\sim 103-108 \mathrm{~K} / \mathrm{s})$ resulting in nonequilibrium solidification conditions [27]. The cell size varies in the molten pools but usually never exceeds 


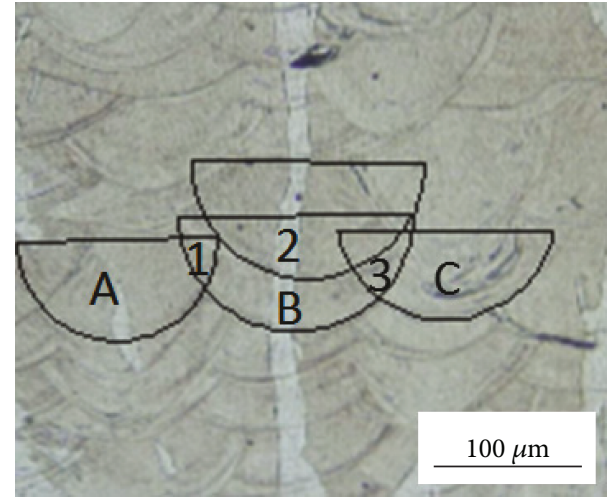

FIGURE 19: The pool boundaries of the sample 2 fabricated by SLM.

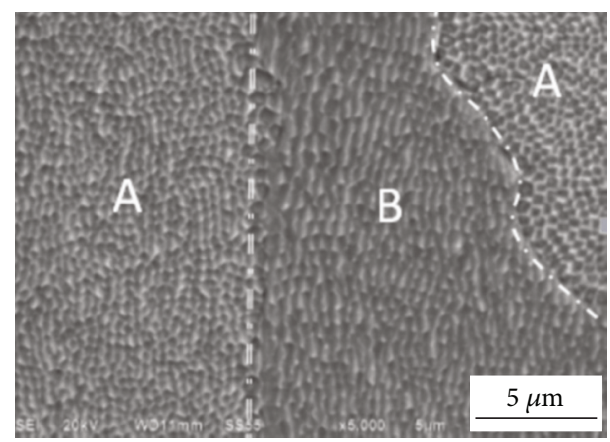

FIgURE 20: Representative SEM images at high magnification showing the typical cellular structure observed in sample 2 .

about $2 \mu \mathrm{m}$. The cell morphology is mainly presented as equiaxed polygons or elongated, depending on the growth direction of the metallographic structures and thermal gradient direction. Besides, the growth direction of cellular dendrites is not only affected by convective heat flux direction but also influenced by the Marangoni flow, which causes heat-mass transfer, hence affecting the growth orientation of dendrites [15].

When the laser scans on the current island, the previous island's boundaries are remelted. Due to the effect of heat accumulation and a high interface stress, defects such as holes and cracks are more easily formed at the boundaries between adjacent islands $[28,29]$, as indicated by the black arrows in Figure 21(a). To further study the effect of scan strategy on the microstructure of the $316 \mathrm{~L}$ steel, the EBSD experiments were conducted, and the results were displayed in Figures 21 and 22. As can be seen, the different scan strategies lead to a different grain growth direction, as shown in Figure 21(b) where the junction zone was a disorder site. We can see from the kernel average misorientation map of the red mark in Figure 21(a) that the stress distribution is higher at the crack in Figures 21(c) and 21(d). Figure 22 displayed the EBSD results of the sample 1 and the grain size distribution of these two samples. We can see from Figure 22(b) that there was a higher stress distribution in sample 1 , which was attributed to the higher temperature gradient, as confirmed by the simulation test. Meanwhile, we can see from
Figure 22(c) that the average grain size for the sample 1 was a little smaller than that of the sample 2 , which also attributes to the difference in temperature gradient.

4.4. Microhardness Tests. The two samples were polished and then measured by the HXD-100TMC microhardness tester. The aim of microhardness tests was to highlight possible differences in microhardness induced by different scanning strategies of the laser beam. Microhardness measurements were carried out on samples produced with S-shaped and island scanning strategies, respectively. Table 3 shows the microhardness results measured on the five sample points (see Figure 23) for the X-Z planes of SLM parts.

It can be seen that with the increasing of the number of scanned islands, the microhardness of parts decreased. Owing to the fact that defects easily occurred in the bonding areas between two neighbor cladding islands, where the grains are coarsening, it causes limited microhardness. The samples under the S-shaped strategy had a higher average Vicker hardness of $265.1 \mathrm{HV}$, and under the island strategy, the average hardness at the boundaries between adjacent islands is $255.1 \mathrm{HV}$. This can be anticipated form the kernel average misorientation results, and higher temperature gradient leads to more dislocations, which can retard or block the migration of newly formed dislocations under external force, leading to a higher microhardness [30]. But overall, the microhardness of SLM parts is relatively uniform, fluctuating within $10 \%$, and is higher than traditional casting parts of about $220 \mathrm{HV}$ [31].

\section{Conclusions}

In the process of SLM, a multitrack and multilayer FEM is established to study the influence of scanning strategy on temperature field distribution and molten pool contours of SLM parts. Furthermore, the corresponding experiment was conducted to verify the FEM. The microstructure of parts is observed, and the experiment results are consistent with the simulation results of the temperature field. The following conclusions can be drawn:

(1) When laser scans a single layer, the maximum temperature is recorded at the start of every track scan and then drops subsequently. Meanwhile, with the increasing number of layers, the maximum temperature increases at first and then decreases because the thermal conductivity of the scanned area is larger than that of the powdered entity.

(2) Grains are mainly made up of columnar crystals and cellular dendrites, growing in the direction of the maximum temperature gradient through the boundaries of the molten pool. Besides, the average grain size for sample 1 was a little smaller than that of sample 2, which was also attributed to the difference in temperature gradient.

(3) The microstructural defects (cracks) are more likely to locate at the bonding areas between two adjacent layers and the boundaries of the various 


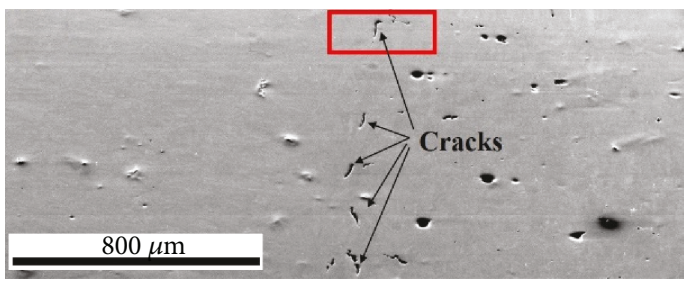

(a)

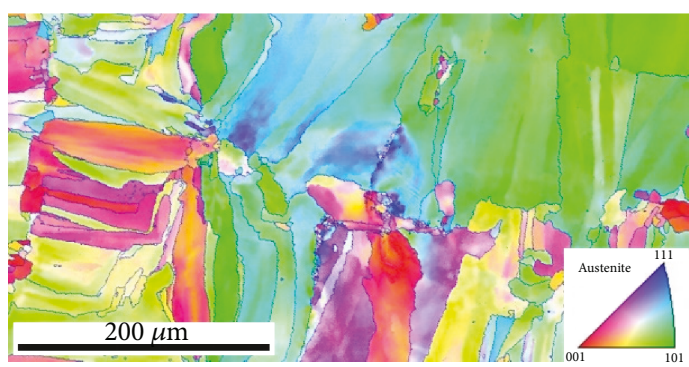

(c)

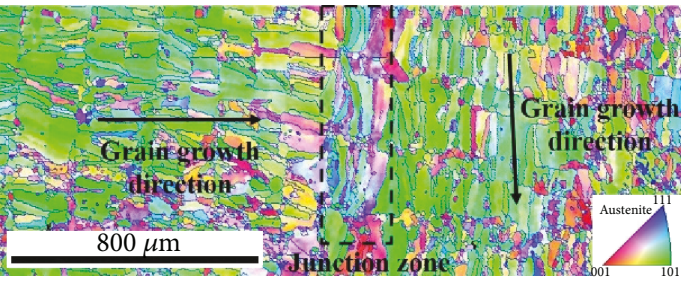

(b)

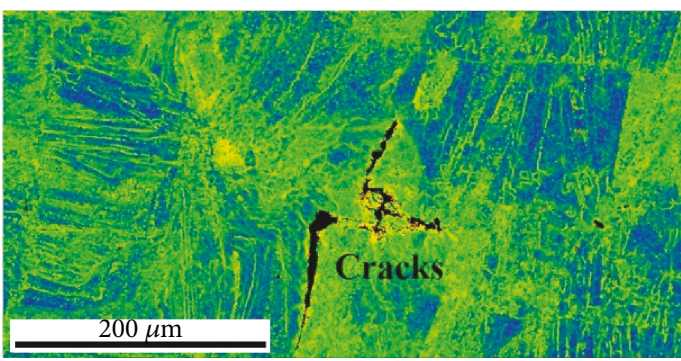

(d)

FIGURE 21: (a) SEM of the junction area in sample 2, (b) inverse pole figure of the junction area, (c) inverse pole figure of the enlarged area in (a), and (d) the kernel average misorientation map.

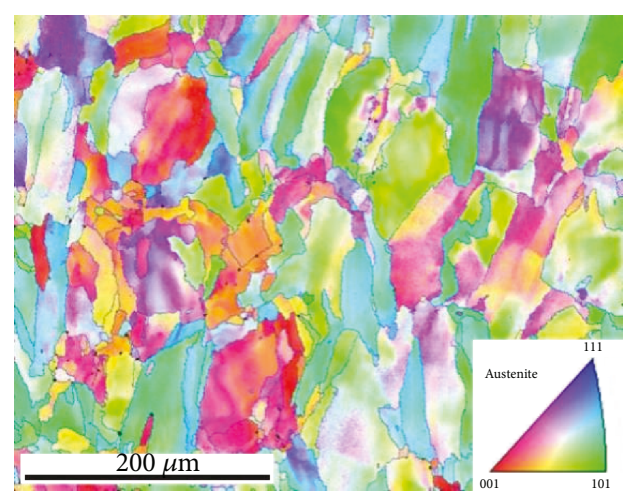

(a)

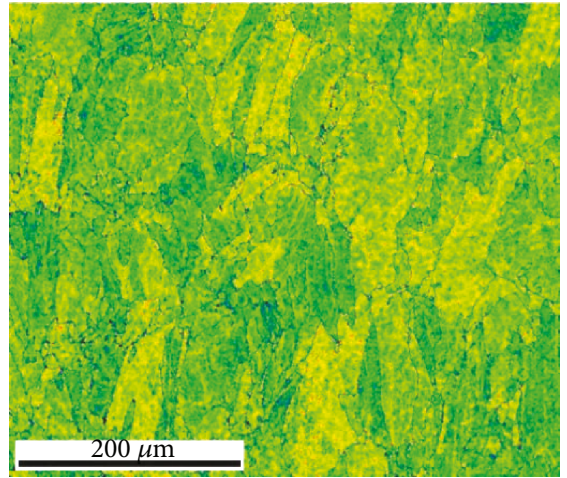

(b)

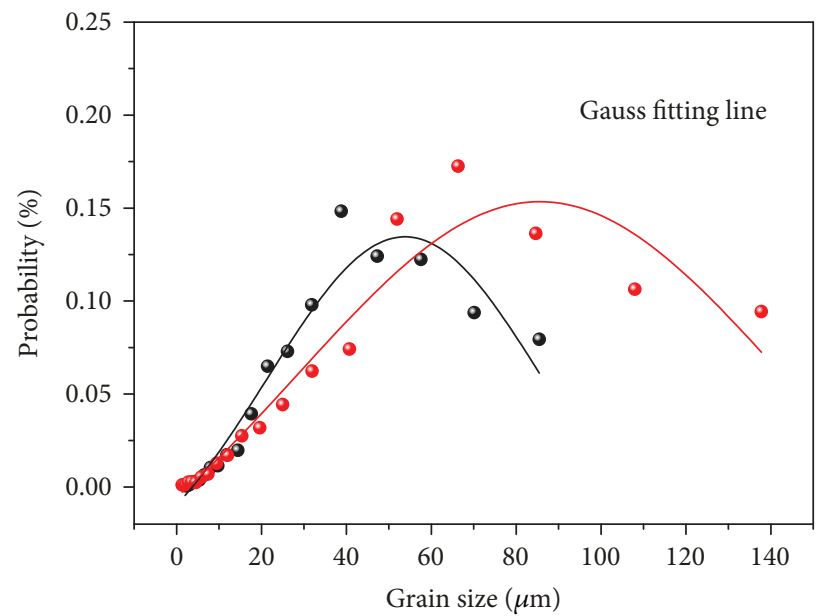

- Sample 1

- Sample 2

FIGURE 22: (a) Inverse pole figures of sample 1 through EBSD and (b) kernel average misorientation map and (c) grain size distribution. 
TABLE 3: Microhardness measures for samples (HV).

\begin{tabular}{lcccccccc}
\hline Sample number & P1 & P2 & P3 & P4 & P5 & Average value & Island number & Scanning strategy \\
\hline 1 & 264.9 & 268.3 & 266.6 & 250.4 & 275.3 & 265.1 & 1 & S-shaped \\
2 & 253.5 & 261.5 & 250.4 & 250.4 & 259.9 & 255.1 & 4 & Island \\
\hline
\end{tabular}

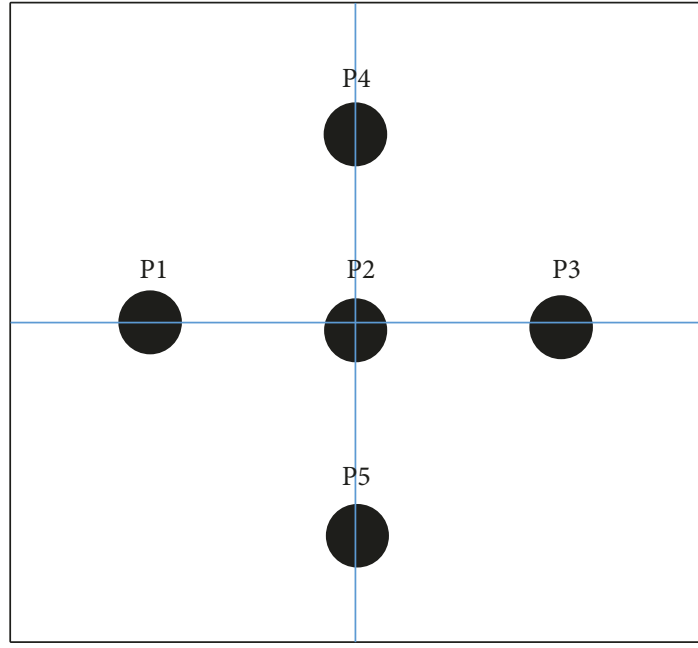

FIGURE 23: Five sample points of parts for microhardness tests.

islands, owing to the effect of heat accumulation at the bonding areas.

(4) The Vicker microhardness at the bonding areas under the island strategy is relatively lower (about 255.1 HV) than that of the SLM 316L parts under the S-shaped scanning strategy $(265.1 \mathrm{HV})$, and the latter was attributed to the higher stress distribution under bigger temperature gradient.

\section{Data Availability}

The data used to support the findings of this study are available from the corresponding author upon request.

\section{Conflicts of Interest}

The authors declare that they have no conflicts of interest.

\section{Acknowledgments}

The work described in this paper was fully supported by Cheng Man and Decheng Kong of USTB. Thanks are due for their technical assistance.

\section{References}

[1] K. V. Wong and A. Hernandez, "A review of additive manufacturing," ISRN Mechanical Engineering, vol. 2012, Article ID 208760, 10 pages, 2012.

[2] S. Mohanty and J. Hattel, "Cellular scanning strategy for selective laser melting: capturing thermal trends with a low-fidelity, pseudo-analytical model," Mathematical Problems in Engineering, vol. 2014, 14 pages, 2014.
[3] L. N. Carter, C. Martin, P. J. Withers, and M. M. Attallah, "The influence of the laser scan strategy on grain structure and cracking behaviour in SLM powder-bed fabricated nickel superalloy," Journal of Alloys and Compounds, vol. 615, pp. 338-347, 2014

[4] E. O. Olakanmi, "Selective laser sintering/melting (SLS/SLM) of pure Al, Al-Mg, and Al-Si powders: effect of processing conditions and powder properties," Journal of Materials Processing Technology, vol. 213, no. 8, pp. 1387-1405, 2013.

[5] E. Liverani, S. Toschi, L. Ceschini, and A. Fortunato, "Effect of selective laser melting (SLM) process parameters on microstructure and mechanical properties of $316 \mathrm{~L}$ austenitic stainless steel," Journal of Materials Processing Technology, vol. 249, pp. 255-263, 2017.

[6] S. A. Khairallah, A. T. Anderson, A. Rubenchik, and W. E. King, "Laser powder-bed fusion additive manufacturing: physics of complex melt flow and formation mechanisms of pores, spatter, and denudation zones," Acta Materialia, vol. 108, pp. 36-45, 2016.

[7] T. Heeling, M. Cloots, and K. Wegener, "Melt pool simulation for the evaluation of process parameters in selective laser melting," Additive Manufacturing, vol. 14, pp. 116-125, 2017.

[8] Q. Shi, D. Gu, M. Xia, S. Cao, and T. Rong, "Effects of laser processing parameters on thermal behavior and melting/solidification mechanism during selective laser melting of $\mathrm{TiC} /$ Inconel 718 composites," Optics \& Laser Technology, vol. 84, pp. 9-22, 2016.

[9] Y. Liu, J. Zhang, and Z. Pang, "Numerical and experimental investigation into the subsequent thermal cycling during selective laser melting of multi-layer 316L stainless steel," Optics \& Laser Technology, vol. 98, pp. 23-32, 2018.

[10] H. Hu, X. Ding, and L. Wang, "Numerical analysis of heat transfer during multi-layer selective laser melting of AlSil0Mg," Optik, vol. 127, no. 20, pp. 8883-8891, 2016.

[11] A. Foroozmehr, M. Badrossamay, E. Foroozmehr, and S.'. Golabi, "Finite element simulation of selective laser melting process considering optical penetration depth of laser in powder bed," Materials \& Design, vol. 89, pp. 255-263, 2016.

[12] A. Hussein, L. Hao, C. Yan, and R. Everson, "Finite element simulation of the temperature and stress fields in single layers built without-support in selective laser melting," Materials \& Design, vol. 52, pp. 638-647, 2013.

[13] L. Parry, I. A. Ashcroft, and R. D. Wildman, "Understanding the effect of laser scan strategy on residual stress in selective laser melting through thermo-mechanical simulation," Additive Manufacturing, vol. 12, pp. 1-15, 2016.

[14] J. Suryawanshi, K. G. Prashanth, and U. Ramamurty, "Mechanical behavior of selective laser melted $316 \mathrm{~L}$ stainless steel," Materials Science and Engineering, vol. 696, pp. 113121, 2017.

[15] D. Wang, C. Song, Y. Yang, and Y. Bai, "Investigation of crystal growth mechanism during selective laser melting and mechanical property characterization of 316L stainless steel parts," Materials \& Design, vol. 100, pp. 291-299, 2016. 
[16] H. S. Tran, J. T. Tchuindjang, H. Paydas et al., " $3 \mathrm{D}$ thermal finite element analysis of laser cladding processed Ti-6Al-4V part with microstructural correlations," Materials \& Design, vol. 128, pp. 130-142, 2017.

[17] Y. Huang, L. J. Yang, X. Z. Du, and Y. P. Yang, "Finite element analysis of thermal behavior of metal powder during selective laser melting," International Journal of Thermal Sciences, vol. 104, pp. 146-157, 2016.

[18] M. A. Doubenskaia, I. V. Zhirnov, V. I. Teleshevskiy, P. Bertrand, and I. Y. Smurov, "Determination of true temperature in selective laser melting of metal powder using infrared camera," Materials Science Forum, vol. 834, pp. 93-102, 2015.

[19] X. Su and Y. Yang, "Research on track overlapping during selective laser melting of powders," Journal of Materials Processing Technology, vol. 212, no. 10, pp. 2074-2079, 2012.

[20] R. Casati, J. Lemke, and M. Vedani, "Microstructure and fracture behavior of $316 \mathrm{~L}$ austenitic stainless steel produced by selective laser melting," Journal of Materials Science \& Technology, vol. 32, no. 8, pp. 738-744, 2016.

[21] K. Darvish, Z. W. Chen, M. A. L. Phan, and T. Pasang, "Selective laser melting of Co-29Cr-6Mo alloy with laser power 180-360 W: cellular growth, intercellular spacing and the related thermal condition," Materials Characterization, vol. 135, pp. 183-191, 2018.

[22] M. Cloots, P. J. Uggowitzer, and K. Wegener, "Investigations on the microstructure and crack formation of IN738LC samples processed by selective laser melting using Gaussian and doughnut profiles," Materials \& Design, vol. 89, pp. 770-784, 2016.

[23] X. Ding and L. Wang, "Heat transfer and fluid flow of molten pool during selective laser melting of AlSi10Mg powder: simulation and experiment," Journal of Manufacturing Processes, vol. 26, pp. 280-289, 2017.

[24] J. A. Cherry, H. M. Davies, S. Mehmood, N. P. Lavery, S. G. R. Brown, and J. Sienz, "Investigation into the effect of process parameters on microstructural and physical properties of 316L stainless steel parts by selective laser melting," The International Journal of Advanced Manufacturing Technology, vol. 76, no. 5-8, pp. 869-879, 2015.

[25] D. Tomus, Y. Tian, P. A. Rometsch, M. Heilmaier, and X. Wu, "Influence of post heat treatments on anisotropy of mechanical behaviour and microstructure of Hastelloy-X parts produced by selective laser melting," Materials Science and Engineering: A, vol. 667, pp. 42-53, 2016.

[26] W. Shifeng, L. Shuai, W. Qingsong, C. Yan, Z. Sheng, and S. Yusheng, "Effect of molten pool boundaries on the mechanical properties of selective laser melting parts," Journal of Materials Processing Technology, vol. 214, no. 11, pp. 26602667, 2014.

[27] T. Vilaro, C. Colin, J. D. Bartout, L. Nazé, and M. Sennour, "Microstructural and mechanical approaches of the selective laser melting process applied to a nickel-base superalloy," Materials Science and Engineering: A, vol. 534, pp. 446-451, 2012.

[28] Y. Lu, S. Wu, Y. Gan et al., "Study on the microstructure, mechanical property and residual stress of SLM Inconel-718 alloy manufactured by differing island scanning strategy," Optics \& Laser Technology, vol. 75, pp. 197-206, 2015.

[29] B. Fotovvati, S. F. Wayne, G. Lewis, and E. Asadi, "A review on melt-pool characteristics in laser welding of metals," Advances in Materials Science and Engineering, vol. 2018, Article ID 4920718, 18 pages, 2018.
[30] D. Kong, X. Ni, C. Dong et al., "Heat treatment effect on the microstructure and corrosion behavior of $316 \mathrm{~L}$ stainless steel fabricated by selective laser melting for proton exchange membrane fuel cells," Electrochimica Acta, vol. 276, pp. 293-303, 2018.

[31] K. Saeidi, X. Gao, Y. Zhong, and Z. J. Shen, "Hardened austenite steel with columnar sub-grain structure formed by laser melting," Materials Science and Engineering: A, vol. 625, pp. 221-229, 2015. 


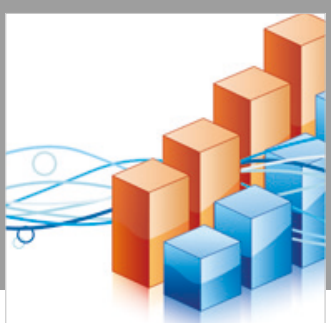

Advances in

Operations Research

\section{-n-m}
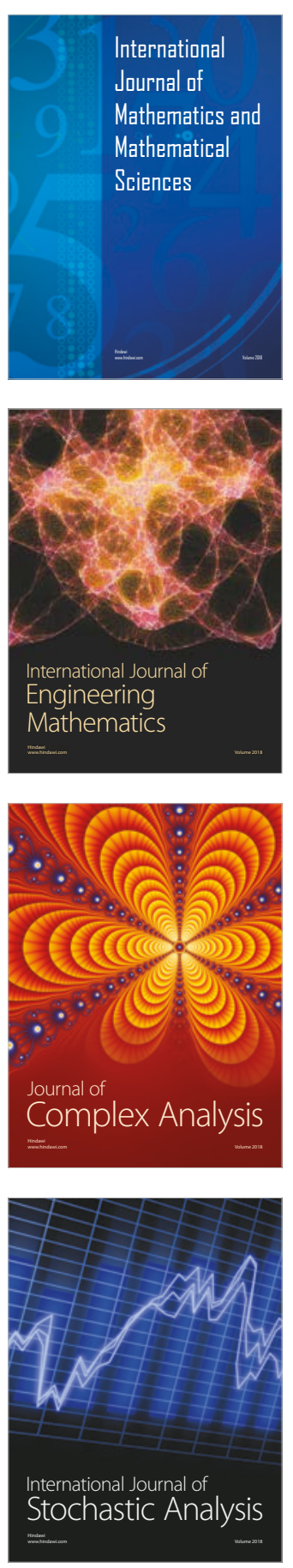
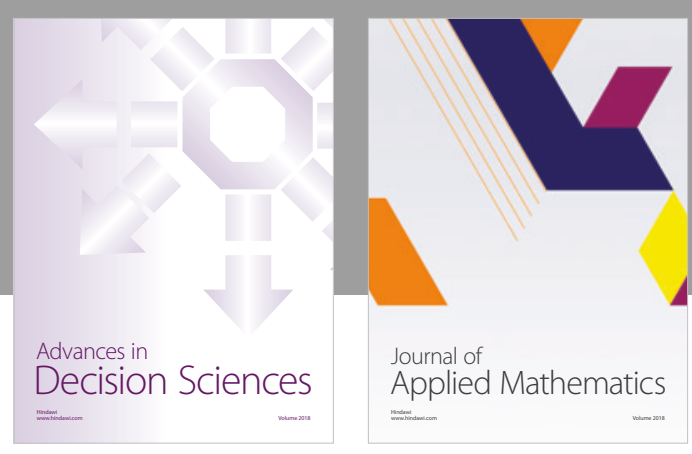

Journal of

Applied Mathematics
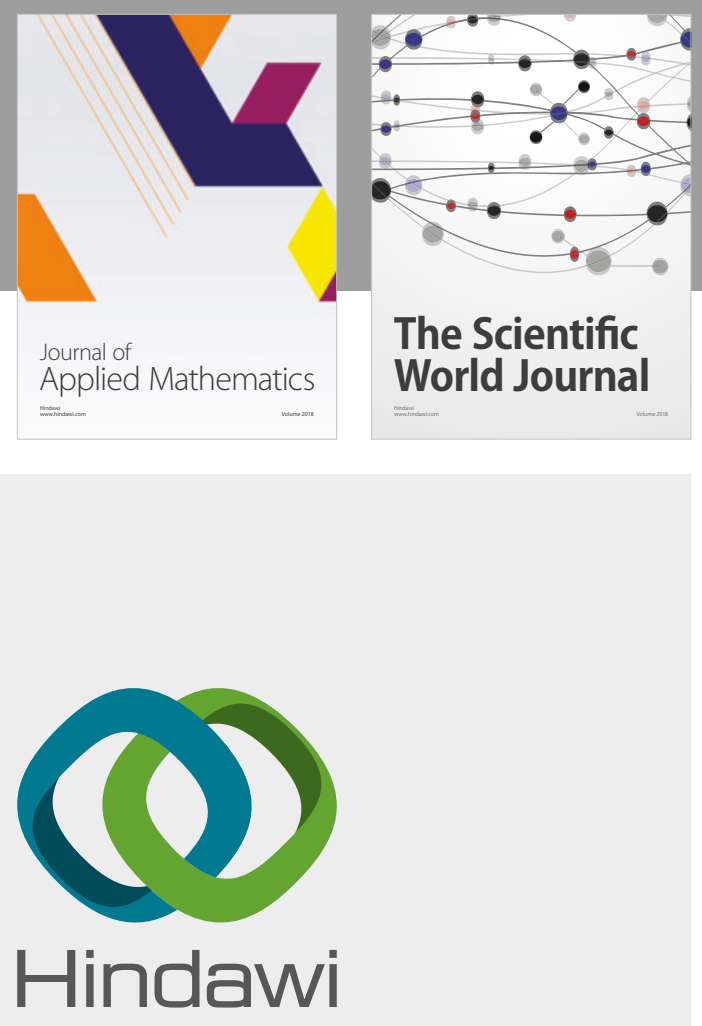

Submit your manuscripts at

www.hindawi.com



Advances in
Numerical Analysis
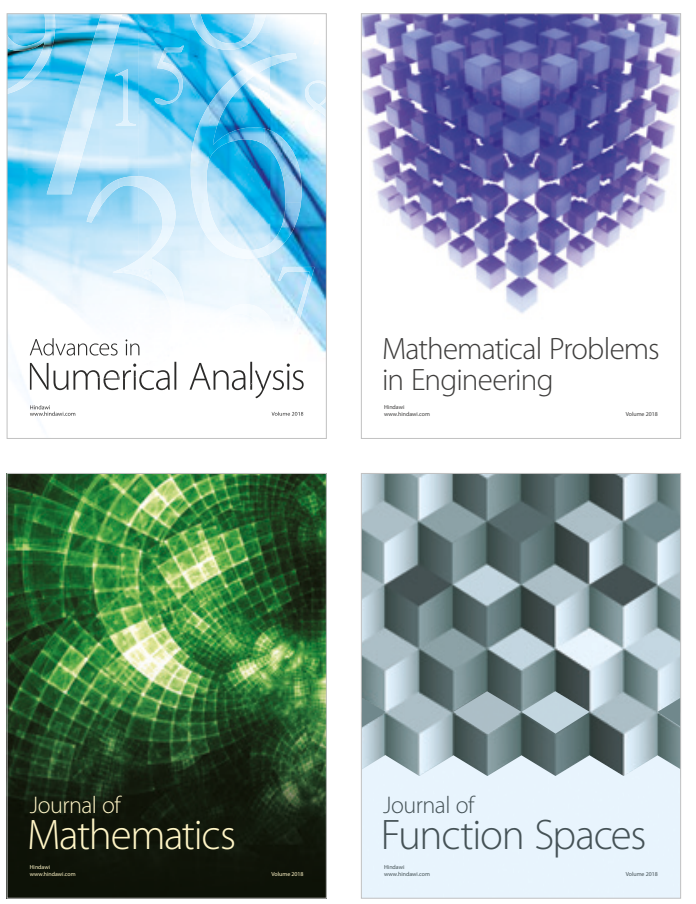

Mathematical Problems in Engineering

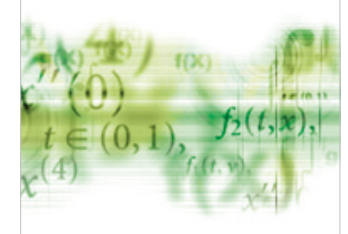

International Journal of

Differential Equations

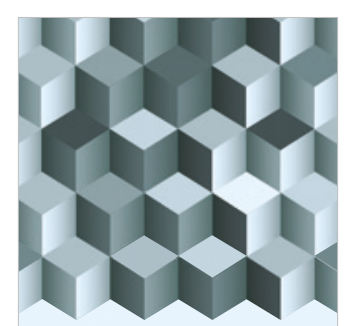

Journal of

Function Spaces
The Scientific

World Journal

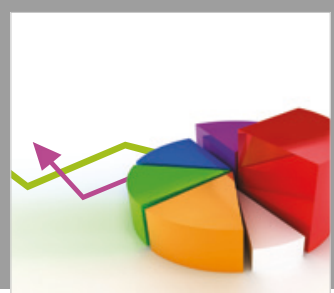

Journal of

Probability and Statistics
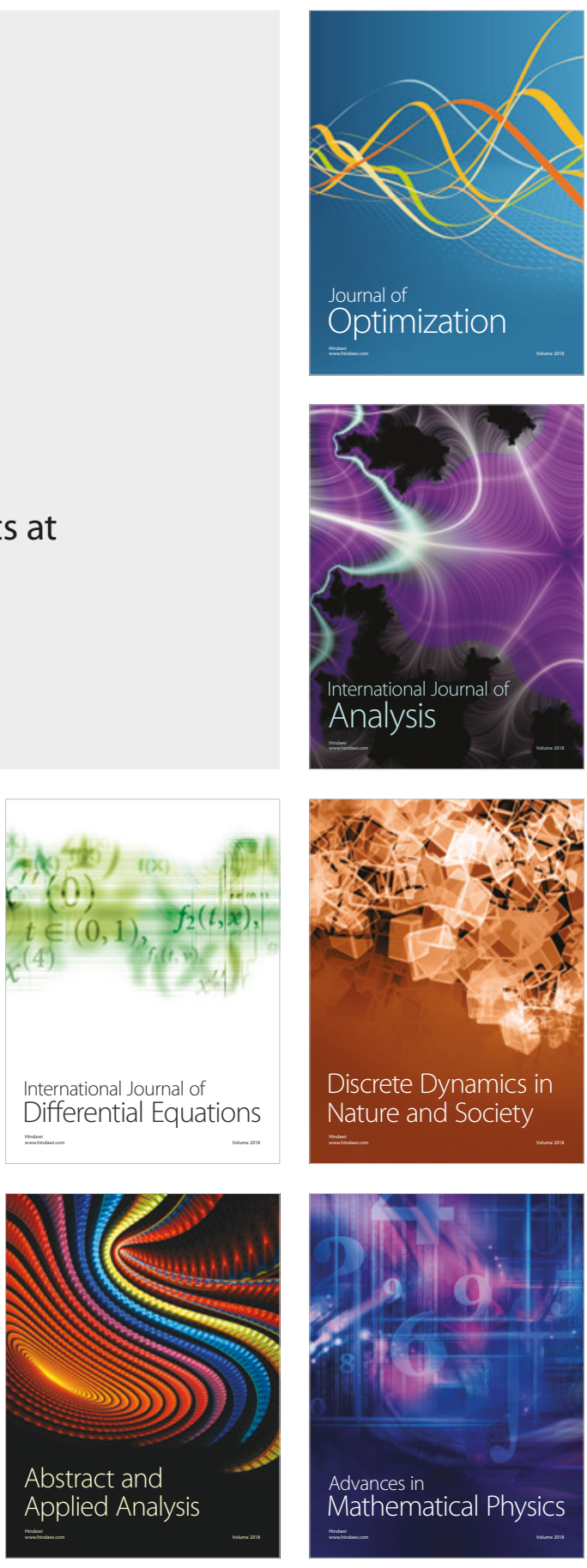